\title{
An Effective Flat Cruciform-Shaped Specimen for Biaxial Testing of CFRP Laminates
}

\author{
Y. Youssef, S. Labonte, C. Roy and D. Lefebvre \\ Departement de génie mecanique, Universite de Sherbrooke \\ Sherbrooke (Québec) Canada JIK 2RI
}

\begin{abstract}
The optimization of a specimen design allowing the investigation of the biaxial strength of composite laminates over the full range of failure strain was the primary objective of this work. Multiaxial strength criteria are often unreliable mainly due to the inherent complexity of biaxial tests and to inefficient specimen designs. Guided by a combination of numerical simulations and experimental measurements, a flat cruciform-shaped specimen configuration has been fabricated with AS4/3501-6 laminates which fulfills three basic criteria namely, homogeneous stress/strain state in the gauge area, the possibility of allowing various biaxiality ratios to develop and the ultimate failure in the virgin material of the gauge area in the tension-tension and tension-compression quadrants of the strain/stress space. The results of a typical biaxial test are discussed to demonstrate the adequacy of the specimen design for strength data generation with composite laminates under biaxial loading conditions.
\end{abstract}

\section{INTRODUCTION}

A decade ago, the AIAA Composite Structures Subcommittee published a survey over 100 members representing a wide cross-section of individuals and groups engaged in structural design and analysis with composite materials / 1 /. One of the main conclusions of the survey revealed that there is little agreement, if any, on common topics such as failure definition, failure criteria, design allowables and analytical assumptions used in structural design with composites. The author emphasized the urgent necessity to formulate standards (some known ASTM standards are not adopted by industrials) for such key properties in order to use the composites to their full potential. Such a normalization should begin with a valuable common failure criterion for structural analysis, which would provide a basis for defining design allowables. Some years later, a researcher from Douglas Aircraft Co. again highlighted the still widespread misunderstanding of composite laminates behaviour $/ 2$. The disagreement amongst composites users covers laminate properties determination, failure theories, and testing procedures. The few ASTM standards, e.g. D3039-76(82), D341075(82) and D2344-84, reporting composite characterization are widely criticized and overlooked by industrials $/ 2 /$.

New or modified failure theories continue to be published $13 /$, yet none of them have proven fully effective under complex biaxial stress-states. There is an obvious need for an effective biaxial specimen together with a reliable test procedure to investigate the strength and the failure mechanisms of composite laminates under biaxial loading conditions.

Recently, several experimental investigations on biaxial behaviour of composite laminates under static and dynamic loads have been carried out $/ 4,5 /$. The thin-walled tubular vessel submitted to a combination of axial tension/compression and internal/external pressure or torsion is the type of specimen favored, although in this case delicate attention to several para- 
meters is imperative, e.g., material layup, thickness to radius ratio, end attachments, reinforcement configuration, complex load introduction device and possible oil contamination. Excellent papers on the results of these investigations with tubular specimens have been reported by a group from the University of Utah /6-8/.

Another type of specimen gaining in popularity is the flat cruciform-shaped specimen. This more attractive concept is related to ease of fabrication and load introduction. It has been used successfully in static and cyclic biaxial testing of metals $19,10 \%$. The specimen is effective if the following conditions are fulfilled: (1) the stress/strain rate developed in the test area must be homogeneous; (2) possibility of allowing various biaxiality ratios to develop, and (3) the failure must be initiated in the gauge area under any biaxiality load combination. The first two conditions were essentially fulfilled by most of the proposed specimen designs in composite materials. However, the third one, which is crucial in evaluating failure theories, has been satisfied only with unidirectional composites /11/. Those investigations involving crossplied or quasiisotropic composites relied on a stress concentrator (notch, hole or crack) to initiate failure in the test area and avoid premature collapse of the specimen $/ 12,13 /$. Therefore the results of these studies cannot fully describe the properties of virgin material.

This paper describes a flat cruciform-shaped specimen and simple testing procedures that were developed at the Universite de Sherbrooke. This type of specimen possesses design characteristics that enable it to be loaded to biaxial tension-tension and tensioncompression stress states and levels to initiate failure in the relatively defect-free material of the gauge area. The biaxial machine is simple to use and allows static or dynamic tests to be carried out under various biaxiality conditions. These testing facilities open new avenues towards fuller comprehension and characterization of composite laminates under biaxial stress states.

\section{SPECIMEN OPTTMIZATION}

The basic design of a flat biaxial specimen is a thin circular or square test area surrounded by a thicker reinforcement material. Two pairs of opposite arms are drawn (cut) in the reinforced section of the specimen in two orthogonal directions (Figure 1).

The first step consisted of a numerical analysis of the specimen geometry, taking into account the reinforcement material layup using a finite element method. Then, successive models were experimentally tested to validate the theoretical approach used to study the behaviour of the material under biaxial strain/stress conditions and to examine the relevance of the various failure theories. The effect of the diameter of a circular gauge, as well as the reinforcement material nature and thickness, on the intensity and the uniformity of the biaxial strain/stress field developed in the test material was investigated numerically and experimentally /14/. The experimental results from eighteen different specimens confirmed the strain/stress distributions calculated by the NASTRANTM FE code; however, every specimen found effectively correct by FE analysis and classical failure theories (Tsai-Hill, Hoffman, TsaiWu) failed prematurely due to stress concentrations in the fillets between adjacent arms. These regions act as coupling media transferring part of each arm's load to the adjacent arm, thus reducing the total load transferred to the gauge area. Moreover, the expansion of the gauge area sides is countered by the transverse shrinkage of the arms due to Poisson's effect and this strain mismatch can induce large shear stresses in the fillets.

Based on the knowledge gained from our earlier studies, the optimization and the development of the final specimen design was realized experimentally. The following basic concepts were introduced gradually in the specimen design and sequentially evaluated by experimentation.

- The gauge area should be square-shaped; this seems more appropriate for developing uniform strain/stress states in a crossplied laminate (even in a circular gauge area, photoelastic strain pattern appeared square-like);

- The material in the reinforced arms and the gauge area should be of the same nature (i.e. AS4/3501-6 in $[0 / 90]_{\mathrm{ns}}$ configuration) although the supplementary thickness would make them stronger;

- The fillet radius should be reduced to a minimum 

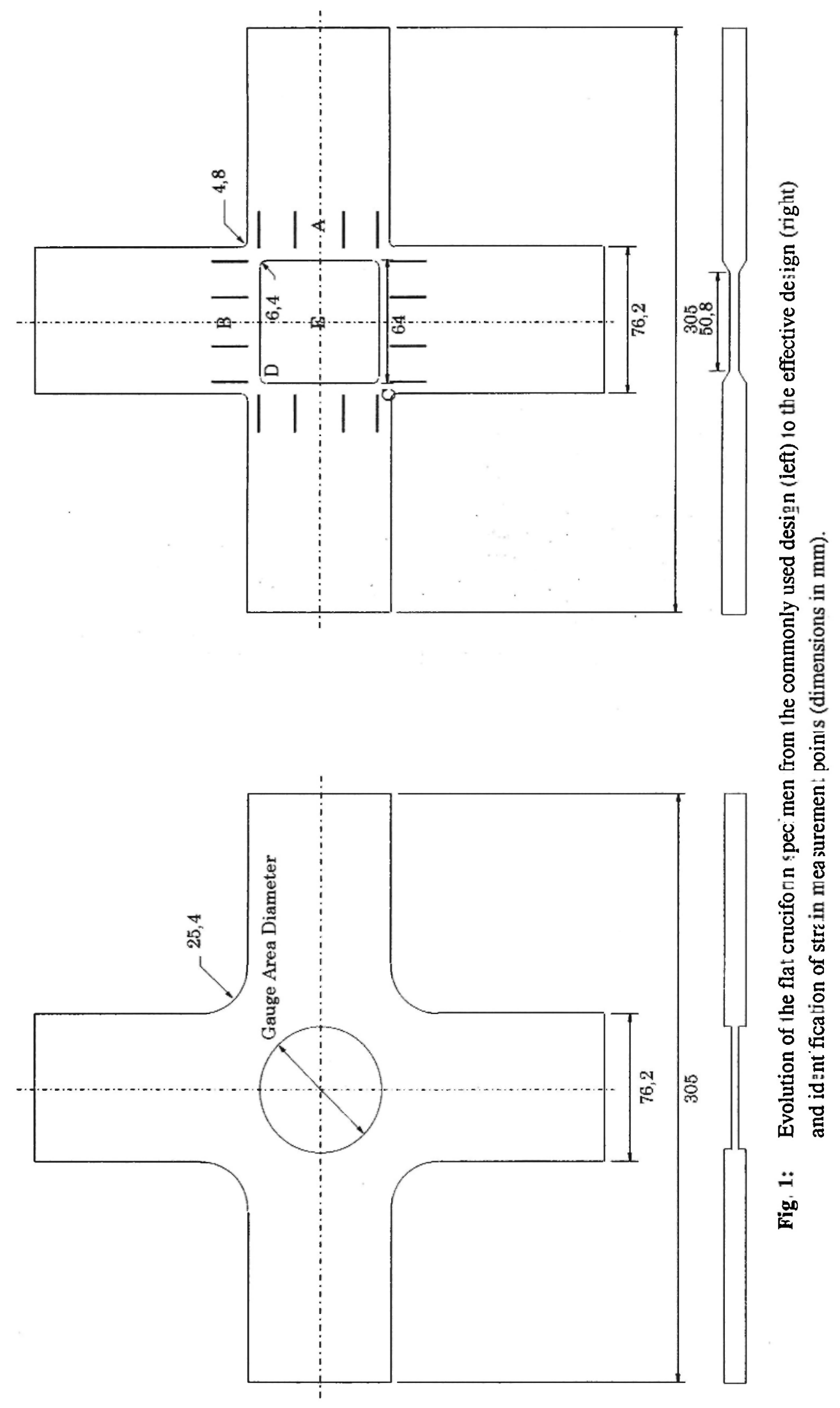
(cutting tool of the smallest possible radius) thus minimizing the coupling effects;

- Gradual cutting out of the laminates between the gauge area and the loaded arms should be emphasized so as to avoid undesirable stress concentration;

- The transverse stiffness of the arms could be reduced without changing their longitudinal stiffness or strength by cutting thin slots in the loading direction.

The evolution of the specimen configuration by introducing sequentially these design concepts is documented in an earlier publication by the authors /15/ and is resumed hereafter: The use of the same CFRP for the specimen reinforcement improved the stress transfer to the central gauge area as higher strains were induced by equivalent forces compared to other specimens. The square gauge area improved the homogeneity of the biaxial strain field developed in this area, although a slight stress concentration appeared in the corners which was minimized by rounding off the edges. The reduced fillet radius did improve the stress transfer to the center of the specimen. In effect, the strain in a given axis was less dependent on the applied load in the other direction, thus indicating a much reduced coupling effect between adjacent arms. Contrary to what one may expect the reduction of the fillet radius did decrease the shear strains measured in that critical region as will be shown later. The slots cut in each arm further improved the homogeneity of the strain field since the strains in the corner were practically identical to those measured in the center of the gauge area. Moreover, the normal strain in each direction was almost independent of the load in the orthogonal direction indicating the elimination of coupling effects. Finally the smooth thickness transition from the gauge area to the loading arms prevented the edge delamination observed in previous specimen designs. These improvements proved effective, as three specimens of the final design were loaded in tensiontension to failure and in all of them the fracture initiated in the gauge area (Figure 2), thus validating the specimen design. Tests in tension-compression quadrants are in progress. The results confirm the predictions and will be published later.

\section{SPECIMEN FABRICATION}

The detailed fabrication procedures were finalized after numerous improvements described in a colleague's master thesis $/ 16 /$. This study involved various fabrication procedures and many parameters such as material combinations, joining procedures, machining methods and parameters. It is suggested that the optimal fabrication procedure consists in machining the specimen from a single composite panel rather than molding or joining pre-machined parts. The protocol is as follows:

The specimen is sawn from a single flat composite panel. This basic plate consists of the laminate to be tested (AS4/3501-6 [0/90 $]_{\mathrm{s}}$ ) confined between the reinforcement parts (AS4/3501-6 [0/90] 3 ). The fabrication steps begin with a rough cut of the specimen outlines using a carbide belt saw. Then the specimen is fixed into a specially designed jig for the remaining fabrication steps which are carried out with a numerically controlled milling machine. Once the specimen outlines are completed, the thickness of the test area is reduced down to the adhesive film on both sides of the specimen using a carbide milling tool. The thin-to-thick material transition band is machined using a cone-ended millstone specially adapted for this purpose. The last and the most time-and-toolconsuming step consists of cutting the slots on the arms using a very small diameter carbide mill. Four slots of $19.05 \mathrm{~mm}$ by $1.15 \mathrm{~mm}$ were cut equidistantly on each arm as shown in Figure 1.

The estimated cost of one specimen fabrication according to the described procedure is approximately 850 Can.\$ (tools and machining time). This unit cost may be considerably reduced as the number of specimens fabricated increases.

\section{TEST PROCEDURE}

The tests are carried out on a biaxial machine equipped with four active servo-valve-controlled hydraulic actuators. Biaxial tests can be run under either force, stroke or strain control with a maximum load of $\pm 250 \mathrm{kN} / 17 /$. For strain measurement, two systems 


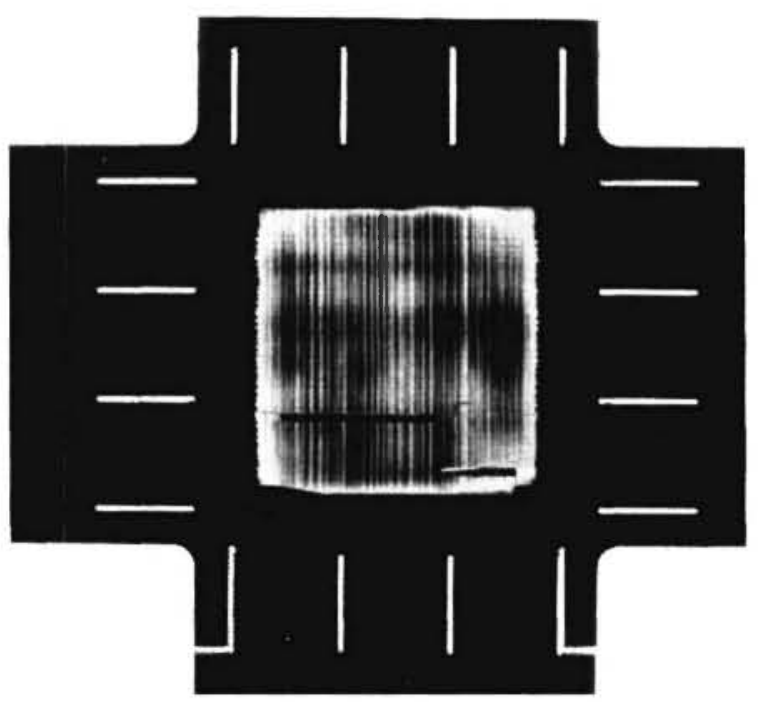

Fig. 2: Photograph of a specimen loaded to failure with $\mathrm{K}_{\mathrm{a}}=2 / 5$.

have been adopted due to the ease of their setting and operation. These two methods are standard strain gauges in $45^{\circ}$-three-element-rosette configuration or the biaxial extensometer developed at the Universite de Sherbrooke specially for use with a flat cruciform specimen /18\%. Strain gauges permit punctual measurement of normal and shear strains at various locations of the specimen: As shown in Figure 1, a maximum of five locations was identified to characterize the strain state in the specimen. They enable analysis of the specimen's behaviour with respect to the biaxiality ratio and the load level. The biaxial extensometer helps to measure global normal strains in two perpendicular directions over the test area. Its usefulness is obvious when the test area should remain free for other types of measurements such as Xray or C-scan monitoring of matrix crack evolution with load history.

Once instrumented, the specimen was set in the biaxial machine and a series of low-load tests were carried out with various values of biaxiality ratios $\left(\mathrm{K}_{\mathrm{a}}=\mathrm{F}_{\mathrm{y}} / \mathrm{F}_{\mathrm{x}}=1 / 20,1 / 10 / 1 / 5,2 / 5,3 / 5,4 / 5,1,5 / 4,5 / 3\right.$, $5 / 2,5,10,20)$ to verify the linearity of the material behaviour, the homogeneity of strain field in the test area, the actual biaxiality ratio and the symmetry of the specimen. Then, the specimen was loaded to failure under a selected value of $\mathrm{K}_{\mathrm{a}}$ to observe its failure locus and to calculate its ultimate strength. In both tests, the applied loads as well as the measured strains were monitored, digitized and stored for further analysis. This procedure generated data to characterize fully the state of strain/stress at any load condition until failure. During the final test, the load-drop detectors were set to unload the specimen as soon as a $2 \mathrm{kN}$ drop was read. However, the energy stored in the material at fracture of the specimen was so high that it was practically impossible to prevent its spontaneous disintegration. Only video recording of the final stages of loading enabled the location of the fracture initiation to be identified by visualizing frame-by-frame events on the film.

\section{TYPICAL RESULTS}

Initially at low load level, the linear stress-strain behaviour of the material in all directions under all biaxiality ratios was verified. Thus each strain component can be represented by its slope when plotted against the applied dominant force $\left(F=F_{x}\right.$ if $K_{a}<1, F_{y}$ otherwise). For various strain components the slopes were plotted against the applied biaxiality ratio $\left(\mathrm{K}_{\mathrm{a}}\right.$ is replaced by $1 / K_{a}$ when $K_{a}>1$ ). Typical graphs are shown in Figure 3 for point $E$ on the specimen. Similar graphs have been drawn for the other points and their repeatability on different specimens was verified, thus validating the state of strain at these points for similar specimens when strain gauges are not used (specimens tested with the biaxial extensometer). The effect of the fillet radius on the stress distribution is illustrated in Figure 4. The values of the strain components at point $\mathrm{C}$ measured on two specimens with different fillet radii $(4.8$ and $25.4 \mathrm{~mm}$ ) clearly show that a smaller fillet radius reduces the shear strains developed in this critical area of the specimen.

Another useful piece of information extracted from these low-load tests is the variation of the effective biaxiality ratio $\left(\mathrm{K}_{\mathrm{e}}=\varepsilon_{\mathrm{y}} / \varepsilon_{\mathrm{x}}\right)$ measured in the center of the specimen which is representative of a major part of the gauge area as a function of the load biaxiality ratio for tension-tension tests. This relation is shown in Figure 5 $\left(\mathrm{K}_{\mathrm{a}}\right.$ and $\mathrm{K}_{\mathrm{e}}$ are replaced by $1 / \mathrm{K}_{\mathrm{a}}$ and $1 / \mathrm{k}_{\mathrm{e}}$ respectively if $K_{a}>1$ ). The fact that the two lines do not coincide can 


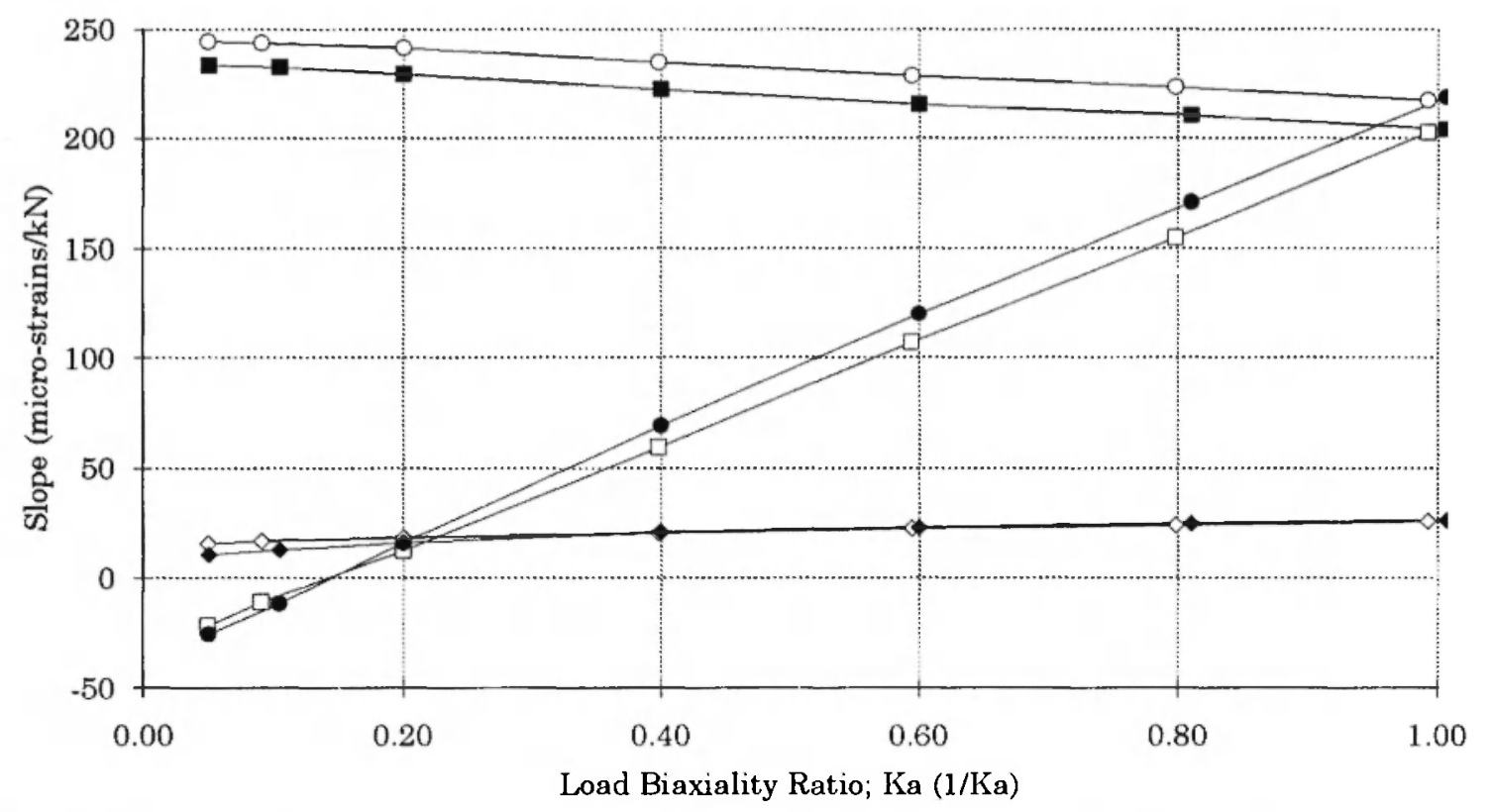

Fig. 3: Values of strain components to dominant force ratio at point $E$ function of $K a\left(\backsim=\varepsilon_{X} / F ; \bullet \equiv \varepsilon_{v} / F ; \mapsto \equiv \gamma_{x v} / F\right.$; dark symbols refer to $K_{a}<1$ while light ones indicate $K_{a}>1$ ).

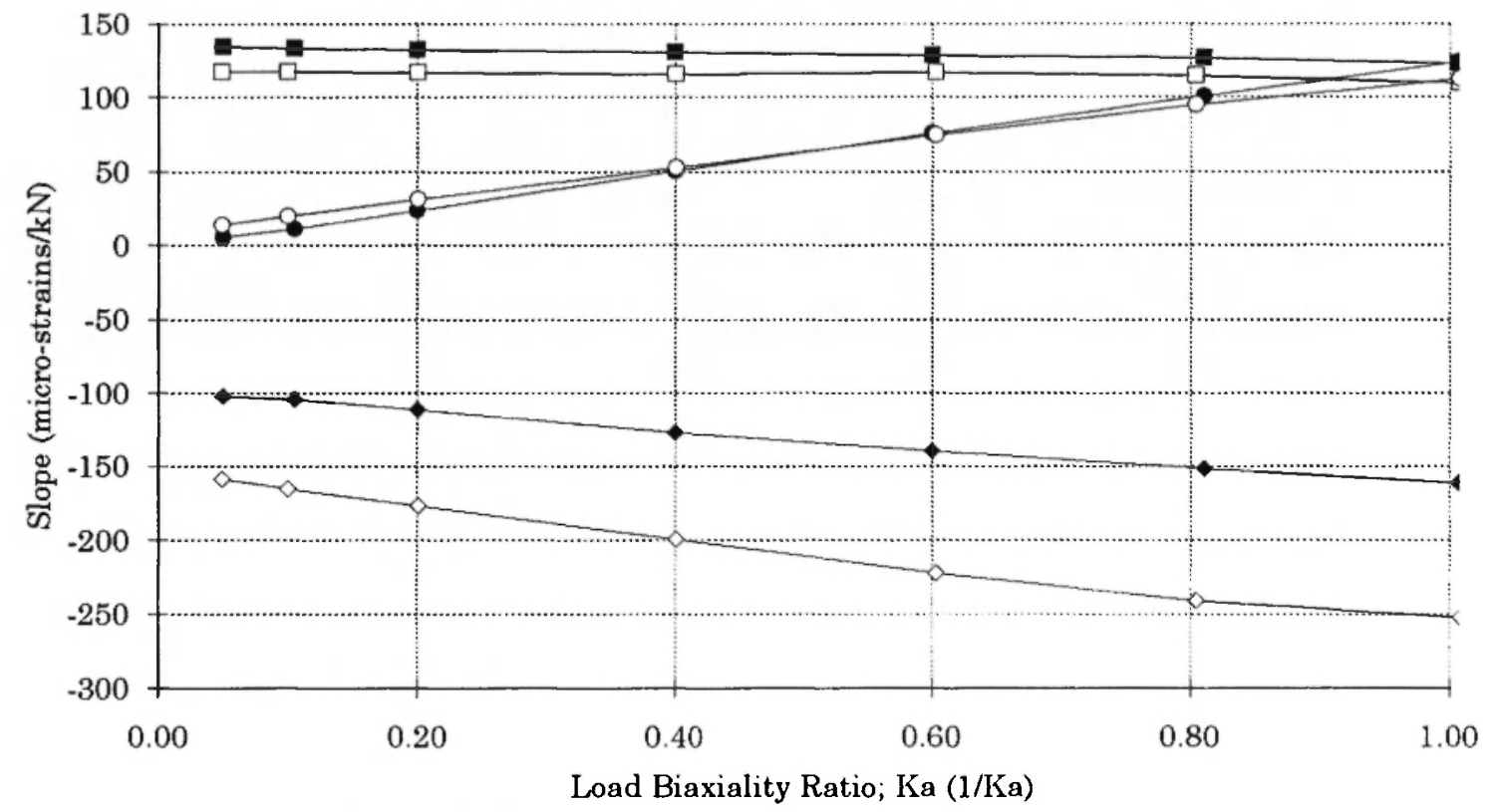

Fig. 4: Values of strain components to dominant force ratio at point $\mathrm{C}$ function of $\mathrm{Ka}\left(\bullet \equiv \varepsilon_{\mathrm{x}} / \mathrm{F} ; \bullet=\varepsilon_{\mathrm{v}} / \mathrm{F} ; \bullet \equiv \gamma_{\mathrm{xv}} / \mathrm{F}\right.$; dark symbols refer to small-fillet-radius specimen and light ones to large-fillet-radius one). 


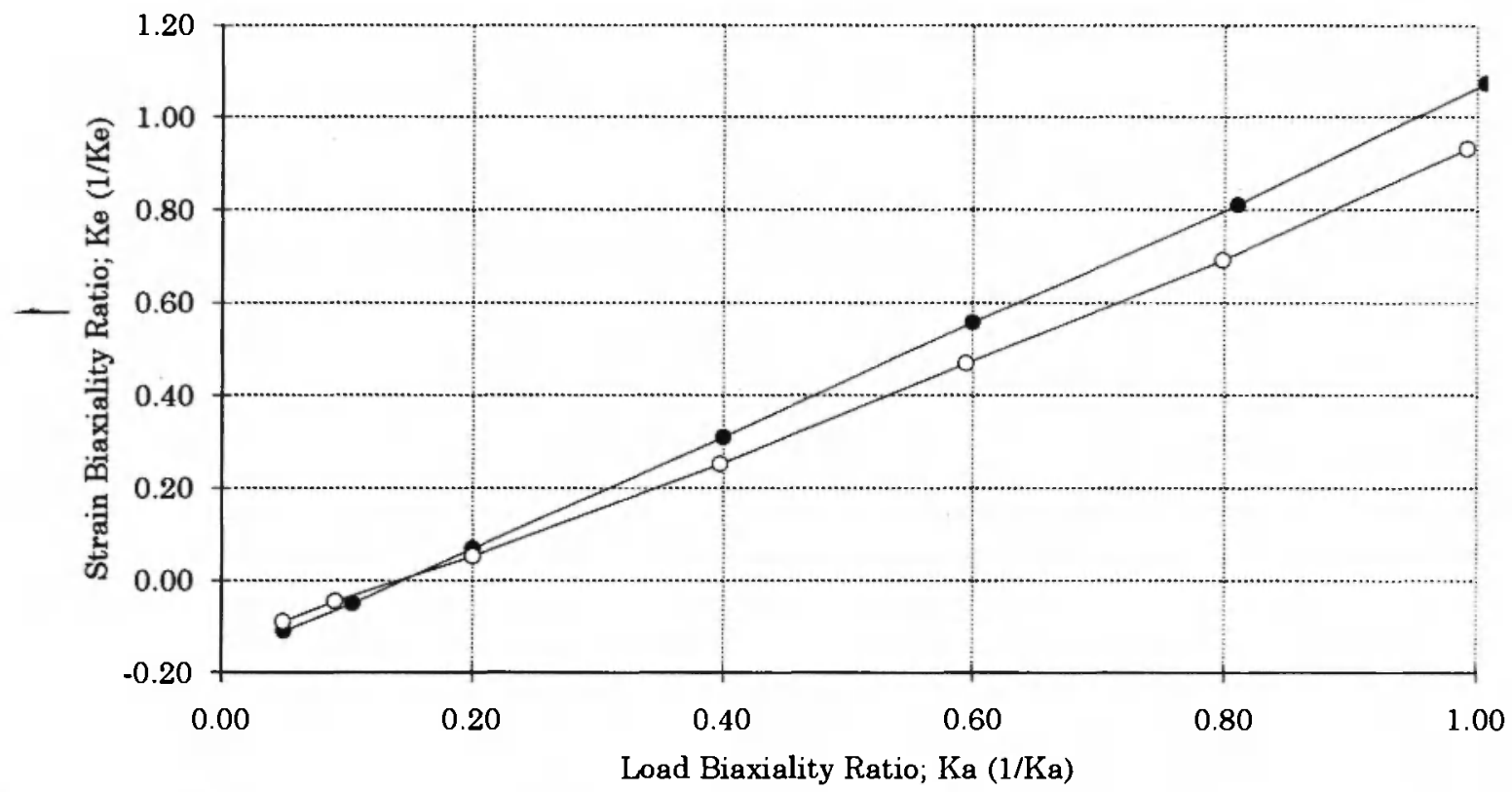

Fig. 5: Strain biaxiality ratio $K_{r}$ function of load one biaxiality ratio $K_{a}$ (dark symbols refer to $K_{a}<1$ while light ones refer to the case of $K_{a}>1$ ).

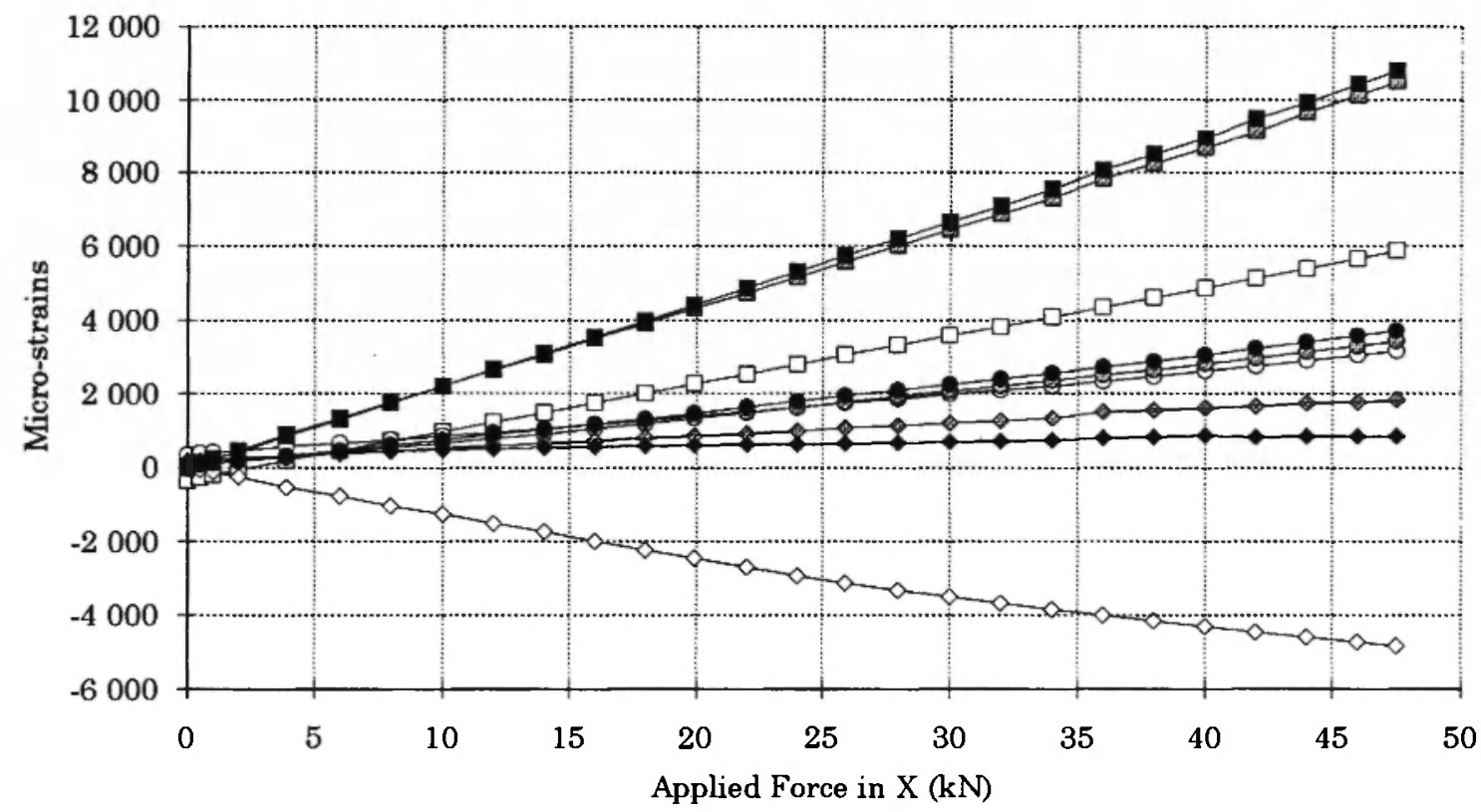

Fig. 6: Strain measurements at points $C$ (light symbols), $D$ (gray) and $E$ (dark) during rupture test with $K_{a}=2 / 5$ (। $\left.=\varepsilon_{\mathrm{X}} ; \bullet=\varepsilon_{\mathrm{v}} ; \bullet=\gamma_{\mathrm{Xv}}\right)$.

be attributed to slight misalignment of the strain gauges with respect to the specimen symmetry axes or of the specimen with respect to the loading axes. This graph is unique for a specimen category and is useful in the selection of a strain biaxiality ratio prior to testing.
Finally, the linear character of the tested material up to rupture can be verified on graphs showing the strain measurements function of the applied load (Figure 6). The material ultimate strains are directly measured, thus enabling failure theory predictions to be 
verified. Preliminary failure results obtained with two identical specimens fall within the scatter of the strength data obtained with tubular specimens of the same material published by Swanson et al. $17,8 /$, thus confirming the adequacy of the specimen design for the generation of valuable strength data of composite laminates under biaxial loading conditions.

The results could also be represented in terms of mean laminate stresses or specific ply stresses since classical lamination theory provides the necessary tools to make the appropriate transformations.

\section{CONCLUSION}

An effective biaxial cruciform-shaped specimen has been developed and tested successfully. Preliminary failure results showed the adequacy of the specimen design for strength data generation with composite laminates under biaxial tension-tension loading conditions. Validation of the specimen in the tensioncompression quadrants is progressing successfully.

Our flat cruciform specimen design is as effective as the tubular type in assessing the strength of composite materials under static biaxial loading and, further, the testing procedure is simpler and safer. The possible range of biaxiality ratios is broad and dynamic-loading can easily be implemented.. In addition to its flexibility, the cruciform specimen design possesses a great cost advantage over the tubular specimen. The latter requires many components and accessories whose complexities contribute to fabrication, assembling and testing costs. The flat specimen design opens up new avenues towards a real comprehension and reliable characterization of composite laminates in biaxial stress states.

\section{ACKNOWLEDGEMENTS}

This work was carried out with financial assistance provided by the National Research Council of Canada under the Institute for Aerospace Research, Structures and Materials Laboratory, Program 3G3: Aerospace Structures, Structural Dynamics and Acoustics, Project JGL, Development of Biaxial Test Capabilities. The authors would particularly like to thank M.D. Raizenne of NCR/IAR SML for his generous contribution to the above work.

\section{REFERENCES}

1. R.C. Burk, Astronaut. \& Aeronaut., 58-62 (June, 1983).

2. L.J. Hart-Smith, "Some observations about test specimens and structural analysis for fibrous compositions", in: ASTM STP 1059, S.P. Garbo (Ed.), ASTM, Philadelphia, 1990; pp. 86-120.

3. R.E. Rowlands, "Strength (failure) theories and their experimental correlation", in: Handbook of Composites, Vol. 3 - Failure Mechanics of Composites, G.C. Sih and A.M. Skudre (Eds.), Elsevier Science Publishers, U.S.A., 1985; pp. 71125.

4. M.S. Found, "A review of the multiaxial fatigue testing of fiber reinforced plastics", in: ASTM STP 853, K.J. Miller and M.W. Brown (Eds.), ASTM, Philadelphia, 1985; pp. 381-395.

5. P.K. Mallick, "Failure of laminated composites in biaxial stress-fields: A review", in: $A S M E$ Pressure Vessels and Piping Division PVPD $v$ 146, ASME, New York, 1988; pp. 205-212.

6. S.R. Swanson, M. Nelson, "Failure properties of carbon/epoxy laminates under tension-compression biaxial stress", Proc. 3rd Japan-US Conf. on Comp. Mater., Japan Society for Composite Materials, Tokyo, 1986; pp. 279-286.

7. S.R. Swanson, A.P. Christoforou, J. Eng. Mater. \& Technol., 109, 12-16 (1987).

8. S.R. Swanson, B.C. Trask, Composites, 19(5), 400-406 (1988).

9. I.H. Wilson, D.J. White, Journal of Strain Analysis, 6(1), 27-37 (1971).

10. G.J. de Jong, Strain, 27(4), 137-142 (1991).

11. Z. Fawaz, Etude analytique, numerique et experimentale portant sur la rupture et la fatigue biaxiales des lamelles renforcees de fibres, Doctoral Thesis, Universite de Sherbrooke, 302 p. (1992).

12. I. Suzuki, "Biaxial testing of composite laminates using cruciform specimens, in: Proc. ICCM-8, 
Hawaii, 1991; pp. 37A1-37A9.

13. G.M. Sluimer, "Experimental evaluation of failure-criteria applied to multi-directional laminates of glass-fibre reinforced polyester (GRP)", in: Proc. ICCM-9, A. Miravete (Ed.), Woodhead Publishing Limited, Zaragoza (Spain), 1993; pp. 907-912.

14. S. Labonte, Y. Youssef, D. Lefebvre, C. Roy and D. Raizenne, "Design, analysis and testing of CFRP cruciform specimens", in: Proc. ICCM-9, A. Miravete (Ed.), Woodhead Publishing Limited, Zaragoza (Spain), 1993; pp. 913-920.
15. Y. Youssef, S. Labonte, D. Lefebvre, C. Roy and D. Raizenne, "Behaviour and fracture strength of carbon/epoxy laminates under biaxial loading", in: CANCOM '93, W. Wallace, R. Gauvin and S.V. Hoa (Eds.), CACSMA, Ottawa (Canada), 1993; pp. 605-613.

16. S. Labonte, Master thesis, to be published, Universite of Sherbrooke, 1994.

17. A. Makinde, L. Thibodeau and K.W. Neale, Experimental Mechanics, 32(2), 138-144 (1992a).

18. A. Makinde, L. Thibodeau and K.W. Neale, Experimental Mechanics, 32(2), 132-137 (1992b). 
